\title{
SPECIES COMPOSITION AND ABUNDANCE OF LEAFROLLERS IN A CANTERBURY PINE PLANTATION
}

\author{
E.G. BROCKERHOFF ${ }^{1}$, H. JACTEL ${ }^{2}$, A.C. LECKIE $^{1}$ \\ and D.M. SUCKLING ${ }^{3}$
}

${ }^{1}$ Forest Research, P.O. Box 29237, Christchurch, New Zealand ${ }^{2}$ Laboratory of Forest Entomology, INRA, 33610 Pierroton, France ${ }^{3}$ HortResearch, P.O. Box 51, Lincoln, New Zealand

Corresponding author: eckehard.brockerhoff@forestresearch.co.nz

\section{ABSTRACT}

Several leafroller species (Tortricidae) are known to occasionally cause considerable defoliation in Pinus radiata plantation forests. We conducted pheromone trapping for five indigenous species, Ctenopseustis herana, Ctenopseustis obliquana, Planotortrix excessana, Planotortrix notophaea and Planotortrix octo, and the exotic Epiphyas postvittana, to determine their abundance in $20 \mathrm{P}$. radiata stands in Eyrewell Forest, North Canterbury. Trapping from December 2001 to February 2002 indicated that E. postvittana and $C$. obliquana were very abundant (with mean catches of 0.77 and 0.44 moths/trap/day, respectively) while the other species were rarely caught. Results for the native leafrollers differ considerably from those reported from other plantation forests and other habitats in Canterbury, such as apple orchards, where $P$. octo and $C$. herana are generally more common.

Keywords: Tortricidae, Ctenopseustis spp., Planotortrix spp., Epiphyas postvittana, Pinus radiata, plantation forest.

\section{INTRODUCTION}

Many leafrollers (Lepidoptera: Tortricidae) are serious agriculture and forestry pests (van der Geest \& Evenhuis 1991). In New Zealand, several species are known to feed on exotic pines, mainly Pinus radiata D. Don, which represent the basis of a substantial planted forest estate of about 1.7 million ha. Three indigenous species, brownheaded leafroller (Ctenopseustis obliquana (Walker)), greenheaded leafroller (Planotortrix excessana (Walker)) and blacklegged leafroller (Planotortrix notophaea (Turner)), as well as the introduced light brown apple moth (Epiphyas postvittana (Walker)), an Australian species, have been reported to cause defoliation and apical bud damage of pines in New Zealand (Kay 1979; Nuttall 1983). However, there is some uncertainty about the identity of the species that occur in plantation forests in Canterbury. The results of a study in Canterbury suggest that Ctenopseustis herana (Felder and Rogenhofer) may be much more common in plantation forests than C. obliquana (Brown \& Suckling 1994), which could be a reflection of the geographic variation in relative abundance of these species. Furthermore, after the publication by Nuttall (1983) it was discovered that what was known as P. excessana actually comprised two species, P. excessana and Planotortrix octo Dugdale (Dugdale 1990). All these species are more or less polyphagous. For example, C. obliquana has been recorded from indigenous plants in 36 families and from numerous exotic trees (Kay 1979), and E. postvittana has an even wider host range (Danthanarayana 1975). These leafrollers are generally better known as pests in fruit orchards, where they more frequently cause economic damage (Wearing et al. 1991).

There are few published studies on leafroller abundance or damage in plantation forests in New Zealand, and the identity of the species has not always been determined in previous studies (e.g. Hosking \& Hutcheson 1987). The objectives of the present study were therefore firstly to establish which leafroller species occur in Eyrewell Forest, a $P$. radiata plantation 
on the Canterbury Plains, and secondly to determine their relative abundance, using pheromone traps.

\section{METHODS}

Trapping took place in 20 P. radiata stands located in eastern Eyrewell Forest in the area between latitude $43^{\circ} 24^{\prime} 30^{\prime \prime} \mathrm{S}-43^{\circ} 25^{\prime} 30^{\prime \prime} \mathrm{S}$ and longitude $172^{\circ} 21^{\prime} 10^{\prime \prime} \mathrm{E}-172^{\circ} 27^{\prime} 00^{\prime \prime} \mathrm{E}$, at an altitude of 70-115 m. The pine stands were all between 22 and 26 years old, with a stocking of 200-300 trees/ha and a variable understorey vegetation. Delta traps with $20 \mathrm{~cm}$ x $20 \mathrm{~cm}$ sticky bases baited with rubber septum lures were attached to a string suspended between two adjacent pine trees, clear of any understorey plants, at about $2 \mathrm{~m}$ above the ground level. Traps were positioned such that the distance from the stand edge and from other traps within the stand was at least $30 \mathrm{~m}$. Rubber septum lures (Thomas, Philadelphia, Pennsylvania) were prepared by adding pheromone in $25 \mu \mathrm{l}$ hexane to septa and evaporating the solvent. Lures for the different species were made up at standard doses as follows: Ctenopseustis herana lures contained $30 \mu \mathrm{g}$ Z5-tetradecenyl acetate (98\% purity, IPO, Wageningen) (Foster \& Dugdale 1988); Ctenopseustis obliquana lures contained $30 \mu \mathrm{g}$ of a mixture of $25 \%$ Z5-tetradecenyl acetate (98\% purity, IPO) and 75\% Z8-tetradecenyl acetate (98\% purity, IPO) (Young et al. 1985); Planotortrix octo lures contained $200 \mu \mathrm{g}$ of a mixture of $50 \%$ Z8-tetradecenyl acetate $(97 \%$ purity, Shin Etsu, Tokyo), and 50\% saturated tetradecenyl acetate (97\% purity, Shin Etsu) (Galbreath et al. 1985); Planotortrix notophaea lures contained $1 \mathrm{mg}$ of Z7-tetradecenyl acetate (97\% purity, Shin Etsu) (Foster \& Dugdale 1988); Planotortrix excessana lures contained $600 \mu \mathrm{g}$ of a mixture of $20 \% \mathrm{Z}$-tetradecenyl acetate (98\% purity, IPO), 30\% Z7-tetradecenyl acetate (98\% purity, IPO) and 50\% saturated tetradecenyl acetate (97\% purity, Shin Etsu) (Galbreath et al. 1985; Foster \& Dugdale 1988); Epiphyas postvittana lures contained 100 ug of a mixture of $95 \%$ E11-tetradecenyl acetate (97\% purity, Sigma, St. Louis, MO) and 5\% E9,E11-tetradecadien-1-yl acetate (95\% purity, Shin Etsu) (Bellas et al. 1983).

Trapping occurred during summer when the males of these tortricids are generally active (e.g. Suckling \& Burnip 1996; Suckling \& Burnip 1997). Traps were installed on 10 December 2001 and were checked on 20-21 December, 28 December, 7 January 2002 and 18-21 January 2002. At every inspection trap positions were rotated, and trap bases were changed on 28 December 2001 or whenever necessary when a large number of catches would reduce trap efficiency. Each of the 20 stands contained one trap over the entire study period for each of three species, $C$. herana, $P$. octo and E. postvittana, which were assumed to be the most common based on previous studies in Canterbury (Suckling et al. 1990; Suckling \& Burnip 1993). Traps for the other three species were placed in only five stands during the first trapping period and were then shifted to another set of five stands after each assessment so that all 20 stands were surveyed during one trapping period. Because $C$. obliquana was very abundant in the first assessment, traps were placed in each of the 20 stands from the second trapping period. To account for these differences in trapping effort among species, trapping data were transformed to catch/trap/day for analysis. SAS Version 8 was used for all statistical analyses.

\section{RESULTS AND DISCUSSION}

Two species, the exotic $E$. postvittana and the indigenous $C$. obliquana, were caught in large numbers during this study (Fig. 1) with a combined total catch of almost 1000 males. By contrast, no $P$. excessana were caught, and catches of the other three species were low, totalling seven $C$. herana, four $P$. notophaea and two $P$. octo. The results show that E. postvittana is about as common (in terms of daily catch/trap) in plantation forests as it is in fruit orchards in Canterbury where it often dominates the leafroller complex (e.g. Suckling et al. 1990; Suckling \& Burnip 1993). The large number of C. obliquana caught at Eyrewell Forest agrees with findings of previous studies that this species can generally maintain high populations in plantation forests (Kay 1979). However, the observation that this species was far more abundant than its sibling species, $C$. herana, contrasts with results from other plantation forests in Canterbury (e.g. around Lincoln) 


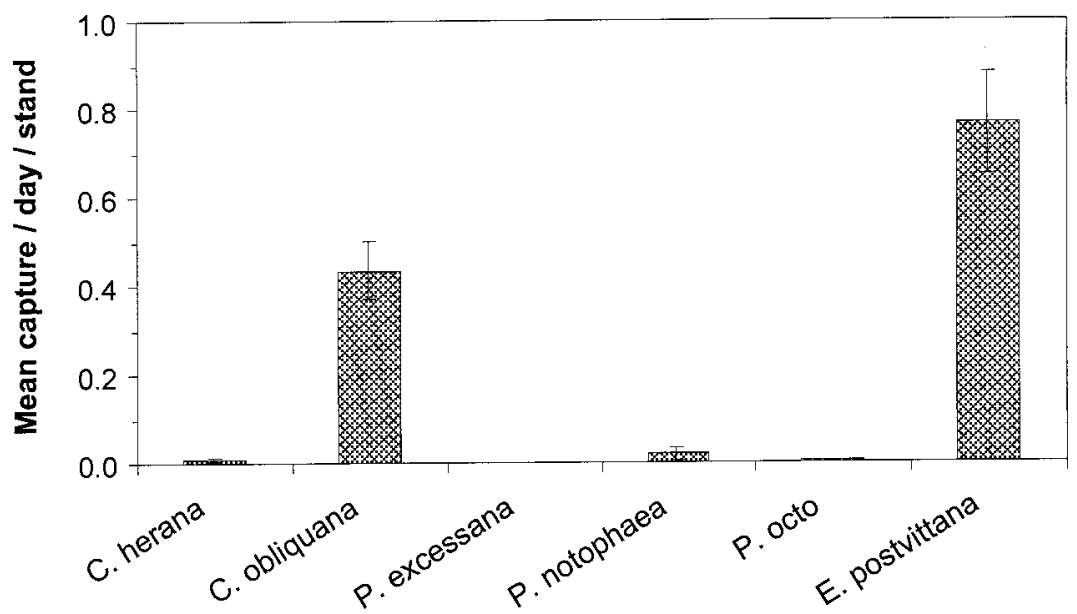

FIGURE 1: Mean $( \pm$ SE) daily catch per trap of Ctenopseustis spp., Planotortrix spp. and Epiphyas postvittana in 20 Pinus radiata stands in Eyrewell Forest, North Canterbury, in December 2001 and January 2002.

(Brown \& Suckling 1994). It is unclear whether this is simply a case of geographic variation, as it is known that the relative abundance of these two species can differ considerably over short distances (Shaw et al. 1994), or whether this is caused by differences in the plant species composition within and around plantations.

In the present study, there was also considerable small scale variation in trap catch for both abundant species, E. postvittana and C. obliquana (Fig. 2). Although both species occurred in each stand, their abundance varied greatly with coefficients of variation of $134 \%$ for $E$. postvittana (range $0.14-2.27$ moths/trap/day) and $113 \%$ for C. obliquana

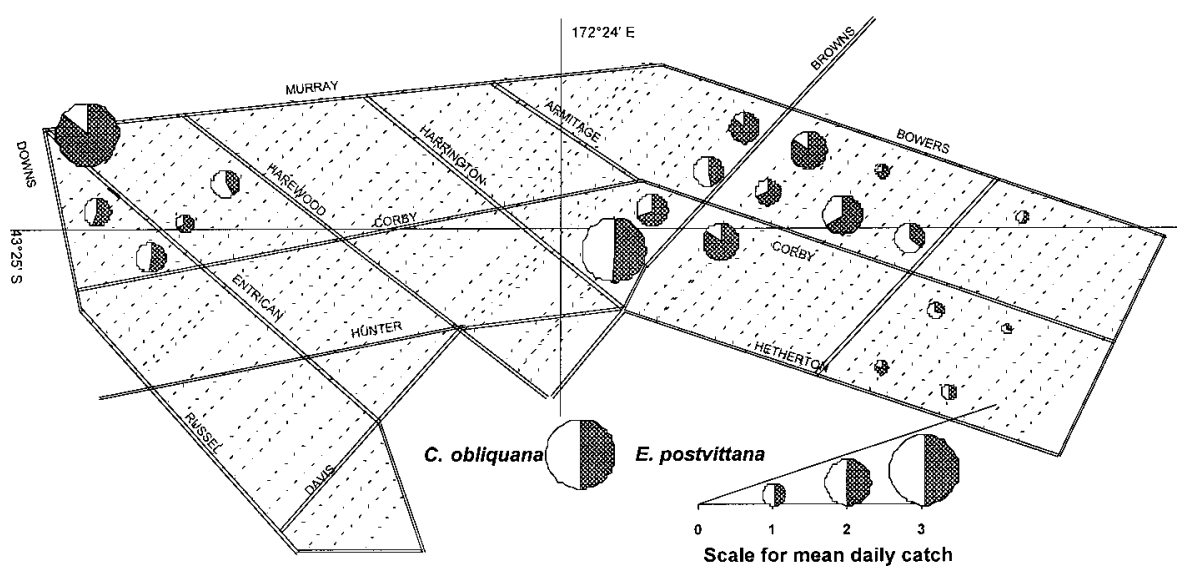

FIGURE 2: Variation in mean daily catch per trap of Epiphyas postvittana and Ctenopseustis obliquana among 20 Pinus radiata stands in Eyrewell Forest, North Canterbury. 
(range $0.10-1.37$ moths/trap/day). There was no significant correlation among stands between the mean daily catches of these two species $\left(R^{2}=0.017, P>0.05\right)$. While all the stands chosen for the present study were of similar age and structure, there were noticeable differences in composition and extent of the understorey vegetation of indigenous and adventive shrubs, herbs and grasses. Such differences are likely to influence the abundance of these polyphagous leafrollers due to variation in the availability of host plants. For example, preliminary analyses indicate that the mean daily catch of $C$. obliquana and the cover of its host plant gorse, Ulex europaeus, (Suckling et al. 1998) are positively correlated in our 20 stands $\left(\mathrm{R}^{2}=0.397, \mathrm{P}<0.01\right)$, although there was no such significant relationship $\left(\mathrm{R}^{2}=0.0003, \mathrm{P}>0.05\right)$ for $E$. postvittana which is also known to feed on gorse.

\section{ACKNOWLEDGEMENTS}

We would like to thank Andy Gibb and Graeme Clare (HortResearch) for provision of the pheromone lures, Tanja Weis for field assistance, John Dugdale for verification of tortricid identification, and John Bain and Bill Faulds for comments on the manuscript. We are grateful for funding provided by the N.Z. Foundation for Research, Science and Technology and the N.Z. Forest Health Research Collaborative.

\section{REFERENCES}

Bellas, T.E.; Bartell, R.J.; Hill, A. 1983: Identification of the two components of the sex pheromone of the moth, Epiphyas postvittana (Lepidoptera, Tortricidae). J. Chem. Ecol. 9: 503-512.

Brown, B.; Suckling, D.M. 1994: Distribution of two Ctenopseustis species (Lepidoptera: Tortricidae) on Banks Peninsula. N.Z. Natural Sci. 21:37-41.

Danthanarayana, W. 1975: The bionomics, distribution and host range of the lightbrown apple moth Epiphyas postvittana (Walker) (Lepidoptera: Tortricidae). Aust. J. Zool. 23: 419-437.

Dugdale, J.S. 1990: Reassessment of Ctenopseustis Meyrick and Planotortrix Dugdale, with descriptions of two new genera (Lepidoptera: Tortricidae). N.Z. J. Zool. 17: 437-465.

Foster, S.P.; Dugdale, J.S. 1988: A comparison of morphological and sex pheromone differences in some New Zealand Tortricinae moths. Biochem. Syst. Ecol. 16: 227232.

Galbreath, R.A.; Benn, M.H.; Young, H.; Holt, V. A. 1985: Sex pheromone components in New Zealand greenheaded leafroller Planotortrix excessana (Lep: Tortricidae). Zeitschr. Naturforsch. 40c: 266-271.

Hosking, G.P.; Hutcheson, J.A. 1987: Lepidopterous defoliators in a developing Pinus radiata stand. N.Z. J. For. Sci. 17: 331-337.

Kay, M.K. 1979: Ctenopseustis obliquana (Walker) (Lepidoptera: Tortricidae), brownheaded leafroller. Forest and Timber Insects in New Zealand, no. 40. Forest Research Institute, Rotorua, New Zealand. 4 p.

Nuttall, M.J. 1983: Planotortrix excessana (Walker), Planotortrix notophaea (Turner), Epiphyas postvittana (Walker) (Lepidoptera: Tortricidae), greenheaded leafroller, blacklegged leafroller, light brown apple moth. Forest and Timber Insects in New Zealand, no. 58. Forest Research Institute, Rotorua, New Zealand. 8 p.

Shaw, P.W.; Cruickshank, V.M.; Suckling, D.M. 1994: Geographic changes in leafroller species composition in Nelson orchards. N.Z. J. Zool. 21: 289-294.

Suckling, D.M.; Burnip, G.M. 1993: Pheromone trapping and insecticide use in Canterbury apple orchards. Proc. 46th N.Z. Plant Prot. Conf.: 129-134.

Suckling, D.M.; Burnip, G.M. 1996: Orientation disruption of Planotortrix octo using pheromone or inhibitor blends. Entomol. Exp. Appl. 78: 149-158. 
Suckling, D.M.; Burnip, G.M. 1997: Orientation disruption of Ctenopseustis herana. J. Chem. Ecol. 23: 2425-2436.

Suckling, D.M.; Burnip, G.M.; Walker, J.T.S.; McLaren, G.F.; Shaw, P.W.; Howard, C.R.; White, V.; Fraser, J. 1998: Abundance of leafrollers and their parasitoids on selected host plants in New Zealand. N.Z. J. Crop Hort. Sci. 26:193-203.

Suckling, D.M.; Thomas, W.P.; Burnip, G.M.; Robson, A. 1990: Monitoring lepidopterous pests at two Canterbury orchards. Proc. 43rd N.Z. Weed and Pest Control Conf: $322-327$

van der Geest, L.P.S.; Evenhuis, H.H. (eds.) 1991: Tortricid Pests: Their Biology, Natural Enemies, and Control. World Crop Pests 5. Elsevier, Amsterdam, The Netherlands. $808 \mathrm{p}$.

Wearing, C.H.; Thomas, W.P.; Dugdale, J.S.; Danthanarayana, W. 1991: Tortricid pests of pome and stone fruits, Australian and New Zealand species. In: van der Geest, L.P.S.; Evenhuis, H.H. ed. Tortricid pests: their biology, natural enemies and control. World crop pests Volume 5. Elsevier, Amsterdam, The Netherlands. Pp. 453-472.

Young, H.; Galbreath, R.A.; Benn, M.H.; Holt, V.A.; Struble, D.L. 1985: Sex pheromone components in New Zealand brownheaded leafroller Ctenopseustis obliquana (Lepidoptera: Tortricidae). Zeitschr. Naturforsch. 40c: 262-265. 